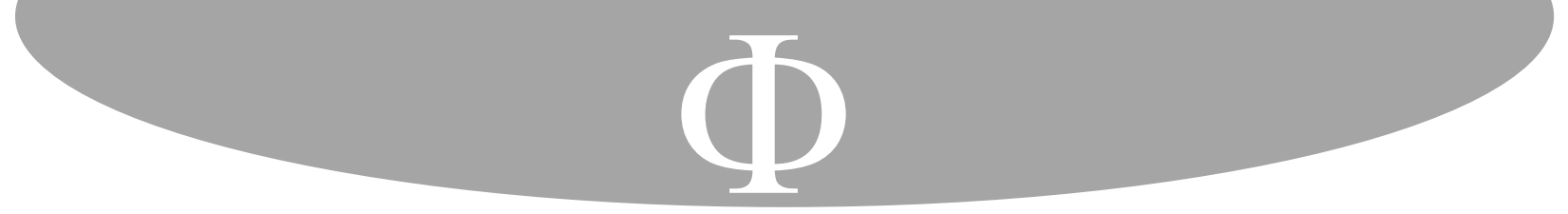

\title{
Análise retórica de Dt 30,11-14
}

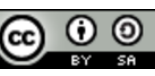

Para citar este artículo: Fernandes, Leonardo Agostini. «Análise retórica de Dt 30,11-14». Franciscanum 176, Vol. 63 (2021): 1-19.
Leonardo Agostini Fernandes*

Pontifícia Universidade Católica do Rio de Janeiro

Rio de Janeiro, Brasil

\section{Resumo}

Após uma breve introdução, apresenta-se a tradução segmentada do texto hebraico com algumas notas de crítica textual. A segmentação facilitou a percepção e a compreensão da forma como o texto está organizado: uma estrutura simétrica. $\mathrm{O}$ estudo prossegue com a análise retórica, individuando, no texto, tanto os elementos da lógica semítica, como da greco-latina. Assim, compreende-se a intenção dessa incisiva fala de Moisés ao povo. Pela natureza narrativa do livro de Deuteronômio e pela posse do livro da torá, o povo experimentará dois acontecimentos: a morte de seu grande líder e a entrada na terra de Canaã sob o comando de um sucessor: Josué.

\section{Palavras-chave}

Análise Retórica, Livro de Deuteronômio, Moisés, «Novo Israel», teologia bíblica.

\section{Análisis retórico de Dt 30,11-14}

\section{Resumen}

Después de una breve introducción, se presenta la traducción del texto hebreo segmentado y algunas notas de crítica textual. La segmentación facilitó la percepción y la comprensión de la forma en que el texto está organizando: una estructura simétrica. Este estudio prosigue con el análisis retórico, pues en el texto se encuentran los principios de la lógica semítica y grecolatina. Así se comprende la intención de este discurso de Moisés. El pueblo, de acuerdo con la naturaleza narrativa del Deuteronomio y la posesión del libro de

\footnotetext{
* Sacerdote da Arquidiocese de São Sebastião do Rio de Janeiro desde 2000. Doutor em Teologia com Especialização Bíblica (Pontifícia Universidade Gregoriana: 2008), Mestre em Teologia Bíblica (Pontifícia Universidade Católica do Rio de Janeiro: 2002), Teólogo (Pontifícia Universidade Católica do Rio de Janeiro: 1999), Bacharel em Catequese Missionária (Pontifícia Universidade Urbaniana: 1993). Docente de Sagrada Escritura no Departamento de Teologia da PUC-Rio. É membro da Associação Bíblica Brasileira (ABIB), da Associazione Biblica Italiana (ABI), da Sociedade de Teologia e Ciências da Religião (SOTER), da Society of Biblical Literature (SBL), e integra o grupo de pesquisa Tradução e Interpretação do Antigo Testamento (TIAT) junto ao CNPq: http://dgp.cnpq.br/dgp/espelhogrupo/9532244382229230. ORCID: https://orcid.org/0000-00032060-8307. Currículo Lattes: http://lattes.cnpq.br/6431968963433274. Contato: laf2007@ puc-rio.br.
} 


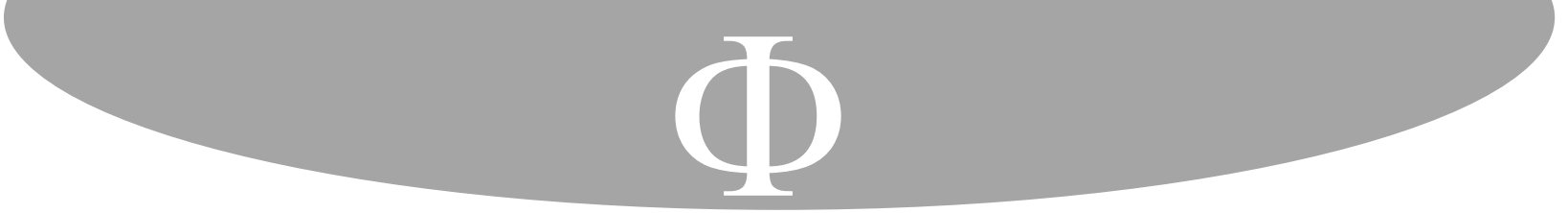

Este parecer, porém, contrasta com a proposta narrativa presente no livro, que apresenta o testamento de Moisés em forma de ensinamentos orais (discursos), algo bem típico da profecia, e todo o seu conteúdo teria transcorrido no dia que chancelou e sigilou o inteiro percurso histórico-literário da Torá: o dia da morte de Moisés (Dt 34) ${ }^{3}$.

Sem adentrar nessa discussão acadêmica, mas seguindo a forma final e canônica, as partes do livro de Deuteronômio podem ser identificadas quer pela presença de um título (Dt $1,1 ; 4,44 ; 28,69 ; 33,1)$, quer pela dinâmica do conteúdo ${ }^{4}$. Com base nesses dois critérios, admite-se que o livro possa ser dividido em cinco partes:

a) Primeiro discurso de Moisés, precedido de um prólogo (Dt 1,1-5), que recapitula elementos importantes do período do deserto (Dt 1,6-4,43);

b) Segundo discurso de Moisés, introduzido por um gancho narrativo (Dt 4,44-49), que reflete sobre a aliança estabelecida no Horeb (Dt 5,1-28,68);

c) Terceiro discurso de Moisés sobre a aliança renovada em Moab (Dt 28,69-30,20);

d) Últimas disposições e ações de Moisés antes de sua morte (Dt 31,1-33,29);

e) Relato da morte de Moisés (Dt 34,1-12).

Segundo essa possível subdivisão, que respeita a índole literária e contribui para a compreensão do conjunto do livro, Dt 30,11-14 pertence ao terceiro discurso de Moisés e, dentro desse contexto, deve-se procurar entender o seu sentido primário e literal. Contudo, essa posição contextual pode ser aprofundada quando são verificadas outras relações plausíveis, em nível sintático-gramatical ad intra, como se procederá ao longo da análise retórica proposta para esse estudo 5 .

A tradução e a subdivisão de Dt 30,11-14, dispostas em vinte e dois segmentos ${ }^{6}$, permite que se perceba a moldura (v. 11.14), que enquadra o desenvolvimento de uma

excelente resumo dedicado à história da pesquisa sobre a formação do livro de Deuteronômio encontra-se em Simone Paganini, Deuteronomio (Milano: Paoline, 2011), 497-510.

${ }^{3}$ A base ad intra, para a questão sobre «o dia da morte de Moisés», encontra-se na locução temporal «hoje mesmo» (הַיוֹם הַזָה), que ocorre onze vezes ao longo do livro (Dt 2,22.25; 3,14; 5,24; 10,8; 11,4; 26,16; 27,9; 29,3; 32,48; 34,6).

${ }^{4}$ Cf. Grazia Papola, Deuteronomio - introduzione, traduzione e commento (Milano: San Paolo, 2011), 17. Há quem subdivida o livro em três partes e considere apenas dois discursos de Moisés, motivado, principalmente, pela forma final do livro de Deuteronômio e da Torá. Cf. Simone Paganini, Deuteronomio, 24-32: abertura (Dt 1,1-5); primeiro discurso (Dt 1,6-4,43); segundo discurso (Dt 4,44-26,19); conclusão (Dt 27,1-34,12). Ao invés de quatro partes, como comumente se apresenta a divisão do livro de Deuteronômio, prefiro considerar Dt 34 um capítulo à parte devido à importância tanto para finalização do livro como para a Torá, pois, certa forma, Dt 34 faz moldura com Dt 1,1-5 e são notórias várias conexões semânticas entre a abertura e o fechamento do livro.

${ }^{5}$ Dt 26,16-19 é relevante para o final do segundo discurso, pois funciona, em tom exortativo, como conclusão de todo o «Código Deuteronômico». Cf. Leonardo Agostini Fernandes, «A atualidade do "hoje" em Dt 26,1619», Pistis \& Praxis 2, Vol. 11 (2019): 378-398.

${ }^{6}$ A segmentação e a análise, que se apresentam nesse artigo, não derivam de alguma versão bíblica já publicada. A tradução é pessoal e foi feita a partir do texto hebraico massorético, segundo o Códex Leningrandense $\left(\mathrm{TM}^{\mathrm{L}}\right)$, 


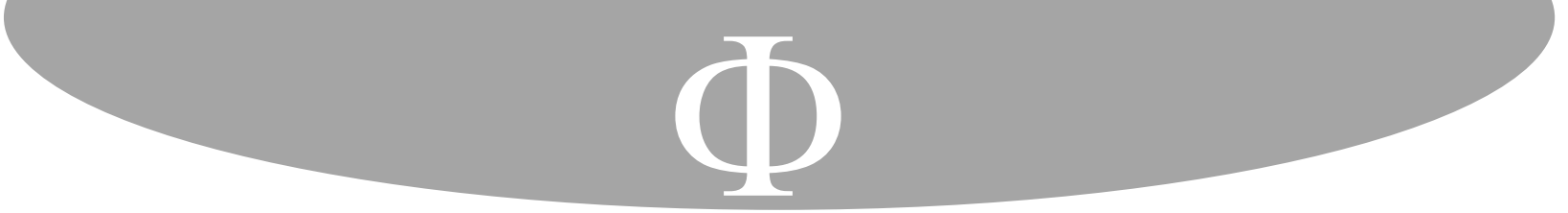

argumentação sem precedentes no livro (vv. 12-13), tornando evidente a relação sinonímica entre os substantivos a ordem e a palavra. Nota-se, ainda, o uso de ideias equidistantes que

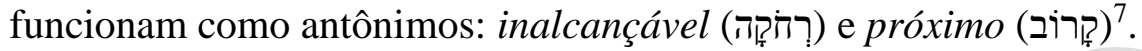

A análise retórica semítica dos textos do AT é uma demanda promissora e que pode ser devidamente valorizada, explorada e aplicada pelos estudiosos de ambos os Testamentos ${ }^{8}$. Graças à utilização da análise retórica evidencia, com mais facilidade, a lógica da composição do texto, a sua estrutura formal, e demarcação dos seus limites.

Nessa análise, o reconhecimento da presença e do uso dos três vetores relacionais: ethos, pathos e logos, permitem perceber que emissor (ethos = sensus/intentio auctoris) $\mathrm{e}$ destinatários (pathos = sensus/intentio lectoris) estão condicionados e envolvidos de forma reciproca e direta pelo conteúdo (logos = sensus/intentio textus). Assim, deve-se reconhecer que, como ponto de partida, sem a intenção do autor não se gera o sentido literal presente no texto e não se chama em causa o interesse pelo leitor.

O passo inicial consiste na análise dos períodos, buscando perceber e compreender a lógica da construção sintático-gramatical presente no texto. Tal foi a metodologia empregada e que validou a aplicação tanto da análise retórica semítica como da análise greco-latina a Dt 30,11-14.

Por meio desse procedimento, acredita-se que as distâncias interpretativas possam ser encurtadas e os resultados possam se tornar mais promissores para as duas vertentes exegético-teológicas. Além da retórica semítica, certos textos do AT também poderiam ser submetidos à análise retórica greco-latina.

\section{Texto segmentado e notas de crítica}

\begin{tabular}{|c|c|c|}
\hline $\begin{array}{l}\text { Portanto }{ }^{9} \text {, } \\
\text { esta ordem }\end{array}$ & $\begin{array}{l}11 \mathrm{a} \alpha \\
11 \mathrm{a} \beta\end{array}$ & 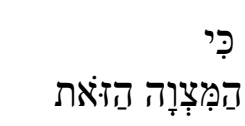 \\
\hline que & $11 b \alpha$ & אָאֶֶׁר \\
\hline eu, hoje, te ordeno, & $11 \mathrm{~b} \beta$ & 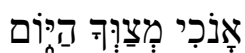 \\
\hline
\end{tabular}

presente na Carmel McCarthy, C. ed. Biblia Hebraica quinta editione (Deuteronomy) cum apparatu critico novis curis elaborato (Stuttgart: Deutsche Bibelgesellschaft, 2007).

${ }^{7} \mathrm{O}$ processo que identifica esta ordem com a palavra prosseguiu com os targumistas, de modo que a palavra se torna a síntese da pregação sobre a legislação contida em todo o livro de Deuteronômio, cf. Rafael Vicent, «Derash Homiletico em Romanos 9-11», Salesianum Vol. 42 (1980): 777.

${ }^{8}$ Cf. Takaaki Haraguchi, «A Rhetorical Analysis of Deuteronomy 29-30», Asia Journal of Theology 1, Vol. 15 (2001): 24-25.

${ }^{9}$ A partícula כִ introduz uma proposição asseverativa e sem fórmula de juramento, podendo ser traduzida pela conjunção «portanto». Cf. Luis Alonso Schökel, Diccionario bíblico hebreo-español (Madrid: Editorial Trotta, 1994), 355-356; Paul Joüon y Takamitsu Muraoka, A Grammar of Biblica Hebrew (Roma: PIB, 2006), §164, 580-582; Carl Martin Follingstad, Deicti Viewpoint in Biblical Hebrew Text: A Syntagmatic and Paradigmatic Analysis of the Particle כ (Dallas: SIL, 2001), 11-13.52. 


\begin{tabular}{|c|c|c|}
\hline ela não é elevada para ti & $11 \mathrm{c}$ & 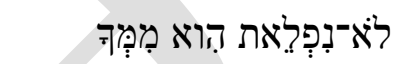 \\
\hline e ela ${ }^{10}$ não é inalcançável. & $11 d$ & וְלא רְחזקָה הִוא: \\
\hline Ela não está nos céus, & $12 \mathrm{a}$ & 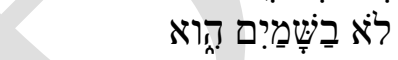 \\
\hline para que perguntes: & $12 b$ & 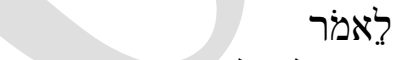 \\
\hline «Quem subirá, por nós, aos céus & $12 \mathrm{c}$ & 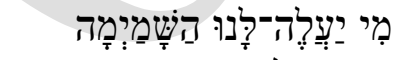 \\
\hline e a buscará para nós, & $12 d$ & 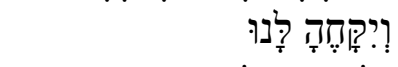 \\
\hline a ela nos fará escutar ${ }^{11}$ & $12 \mathrm{e}$ & 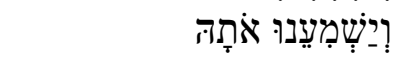 \\
\hline e a praticaremos? ${ }^{12} \gg$ & $12 \mathrm{f}$ & 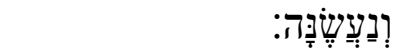 \\
\hline E ela não está ao extremo do mar, & $13 \mathrm{a}$ & 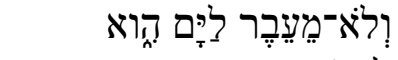 \\
\hline para que perguntes: & $13 b$ & לאלור \\
\hline «Quem atravessará, por nós, & $13 \mathrm{c} \alpha$ & מִי יַעְבָרָר־ְנוּ \\
\hline até o extremo do mar & $13 \mathrm{c} \beta$ & אֶל־עֶרֶר הַיָם \\
\hline e a buscará para nós, & $13 d$ & 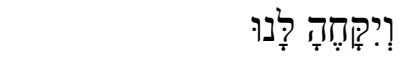 \\
\hline a ela nos fará escutar & $13 \mathrm{e}$ & 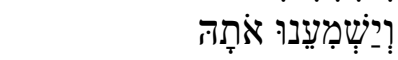 \\
\hline e a praticaremos?» & $13 f$ & 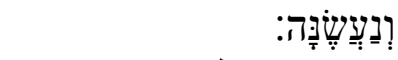 \\
\hline Porque muito próxima de ti está a palavra, & $14 \mathrm{a}$ & 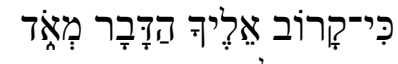 \\
\hline na tua boca e no teu coração ${ }^{13}$ & $14 b$ & 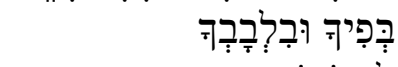 \\
\hline para que a pratiques ${ }^{14}$ & $14 \mathrm{c}$ & לַעְשׁתוֹ: ס \\
\hline
\end{tabular}

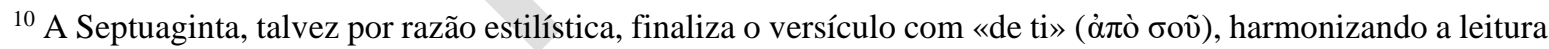

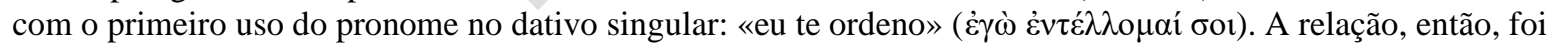
deslocada da ordem para o sujeito que deve cumpri-la. Além disso, essa lição oferece suporte para a variante encontrada em Qumran na 4QDeut ${ }^{\mathrm{b}}$. Cf. Félix García Martínez, «Les manuscrits du Désert de Juda et le Deutéronome», en Studies in Deuteronomy in honour of C. J. Labuschagne on the occasion of his 65th birthday, ed. F. García Martínez; A. Hilhorst; J. T. A. G. M. Van Ruiten; A. S. Van Der Woude (Leiden: E. J. Brill, 1994), 63-82. Um número de manuscritos da Septuaginta, porém, deslocou ònò бoṽ para manter a ordem das palavras do Texto Massorético. Cf. Cécile Dogniez et Marguerite Harl, La Bible d'Alexandrie - Le Deutéronome (Paris: Les Éditions du Cerf, 1992), 308-309; Carmel McCarthy, Deuteronomy - Biblia Hebraica quinta editione cum apparatu critico novis curis elaborato, 87.133.

${ }^{11}$ Outra tradução, para esse caso e do v. 13e, poderia ser: nos fará escutá-la.

${ }^{12}$ Os verbos em hebraico não assumem sufixos duplos como objeto. Cf. Paul Joüon y Takamitsu Muraoka, $A$ Grammar of Biblica Hebrew, $\S 61 \mathrm{j}, 181$.

${ }^{13}$ A lição do Texto Massorético - «no teu coração» (萑) - é sustentada pelo Pentateuco Samaritano, pela Vulgata, pela Peshita, pelo Targum Onqelos e Targum Neofiti. A Septuaginta, por sua vez, possui uma lição

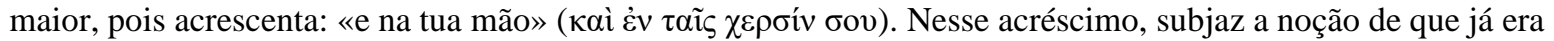
possível ter o livro em mãos. A presença da mesma lição: «e na tua mão», também em 4QDeut confirma essa noção. Cf. Carmel McCarthy, Deuteronomy-Biblia Hebraica quinta editione cum apparatu critico novis curis elaborato, 87.133. Esse dado é relevante, pois no período macabaico, que coincide com o surgimento da Septuaginta e da comunidade de Qumran, houve um decreto de morte de Antíoco IV Epifanes para quem fosse encontrado com uma cópia da Torá (1Mc 1,56-57).

${ }^{14}$ Nem sempre é possível traduzir os verbos em hebraico de um modo totalmente condizente com a forma

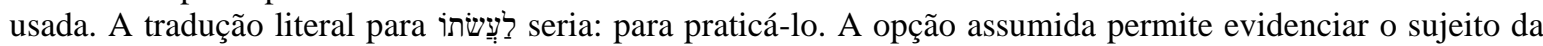
ação, tu, e seu objeto que, nesse caso, é a palavra. Com isso, se estabelece, igualmente, a relação com a tradução de לאמל, assumida nos vv. 12b.13b (GHG, § 58). 


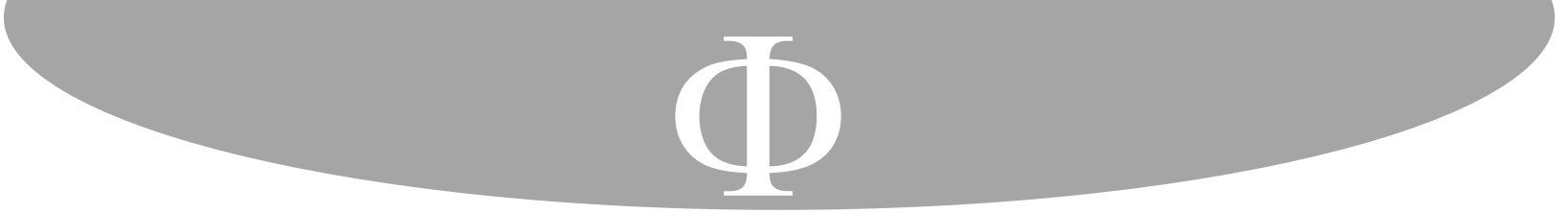

\section{Organização do texto}

Dt 30,11-14 contém repetições, ampliações e paralelismos em função da lógica do seu conteúdo, bem como apresenta cinco frases nominais (vv. 11cd.12a.13a.14a), que poderiam ser traduzidas quer pelo presente, quer pelo futuro ${ }^{15}$. Essa possibilidade permite que as palavras de Moisés sejam entendidas, de forma direta, em referência ao «hoje» dos que contraem a aliança em Moab, com base na lógica profética presente em Dt 30,1-10, mas também permite que sejam assumidas, em qualquer época, no «hoje» dos futuros destinatários ${ }^{16}$, em particular naquele que se fizer obediente por um amor incondicional ao Senhor. Uma estrutura simétrica permite visualizar a lógica interna ${ }^{17}$ :

A: Portanto, esta ordem... (v. 11);

B: ela não está nos céus... para que perguntes (v. 12ab);

C: Quem subirá... aos céus e a buscará para nós (v. 12cd);

D: a ela nos fará escutar e a praticaremos? (v. 12e);

B': E ela não está ao extremo do mar... para que perguntes (v. 13ab);

C': Quem atravessará... mar e a buscará para nós (v. 13cd);

D': a ela nos fará escutar e a praticaremos? (v. 13e);

A': Porque, muito próxima de ti está a palavra... (v.14).

Quanto à moldura (vv. 11.14), o primeiro elemento, que a sustenta, surge na dupla ocorrência da conjunção $k \hat{\imath}$ ('כ) ), e na relação que se estabelece entre os substantivos que estão

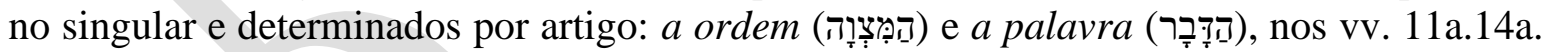
Além disso, a determinação do substantivo ordem recebe uma qualificação a mais, graças ao pronome demonstrativo feminino, com valor de adjetivo atributivo devido ao artigo (הזה: No v. 14a também se encontra uma qualificação para o substantivo palavra, ao se afirmar

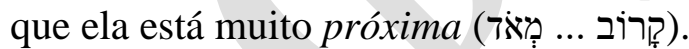

O segundo elemento, que confirma a moldura, se encontra na dupla relação que se

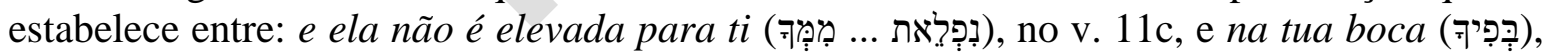

\footnotetext{
${ }^{15}$ Nas traduções prevalece a opção pelo presente, talvez pela dependência da Septuaginta, mas, ao se considerar uma possível ligação de Dt 30,11-14 com a seção precedente (vv. 1-10), que segue a lógica profética, e admitindo-se que a conjunção ’ִ̣, que abre o primeiro segmento do v. 11a, não seja só causal, então a tradução pelo futuro se fundamenta, pois as frases nominais estariam concordando com o uso dos verbos no $\mathrm{w}^{\mathrm{e}} \mathrm{q}$ atal dos vv. 12-13. Cf. Steven R. Coxhead, «Deuteronomy 30:11-14 as a prophecy of the new covenant in Christ», Westminster Theological Journal 2. Vol. 68 (2006): 305-311.

16 Para Thomas Römer, The So-Called Deuteronomistic History. A sociological, historical and literary introduction (New York: T\&T Clark, 2007), 174: «Deuteronômio 30,11-14 se dirige à elite que regressou de Babilônia, sublinhando como ela é e deva ser distinta dos outros povos, pois tem "acesso direto" à palavra e à vontade divina». Ao lado disso, pode-se admitir que os repatriados já possuíam, nas mãos um livro legislativo. Cf. Nehama Leibowitz, Studies in Devarim - Deuteronomy (Jerusalem: Alva Press, 1980), 321-326; Patrick D. Miller, Deuteronomio (Torino: Claudiana, 2008), 225.

${ }^{17}$ Em geral, admite-se uma estrutura simétrica simples: A (v. 11) - B (v. 12) - B' (v. 13) - A' (v. 14), sem evidenciar os possíveis desdobramentos. Cf. Timothy A. Lenchak, "Choose Life!». A Rhetorical-Critical Investigation of Deuteronomy 28,69-30,20 (Roma: PIB, 1993), 178-179; Grazia Papola, L'Alleanza di Moab Studio exegético teológico di Dt 28,69-30,20 (Roma: PIB, 2008), 226-227; Gabriele Corini, Dt 28,69-30,20: la nuova alleanza in Moab. Israele tra memoria e identità (Milano: Glossa, 2010), 21.
} 


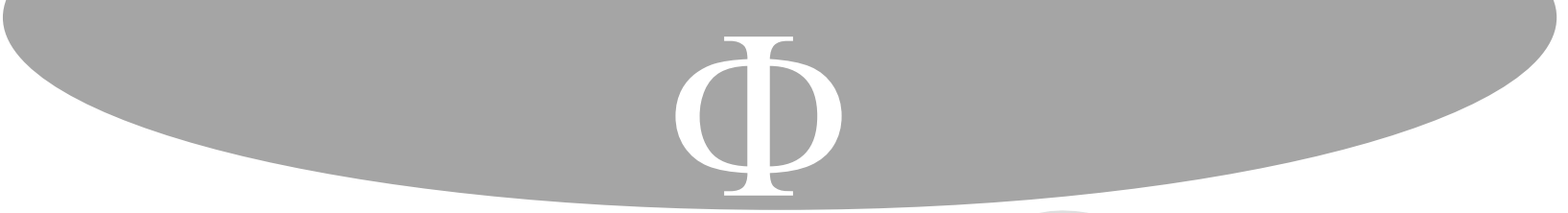

Com isso, se tem a confirmação do que se pretendeu alcançar entre a ordem e a palavra: uma síntese de toda a legislação presente no livro de Deuteronômio ${ }^{19}$, pois a ordem, que expressa a vontade de Deus, aponta para a «encarnação» da palavra. Pela índole interna e literária, Dt 30,11-14 pode ser classificado como uma exortação de natureza proverbial ${ }^{20}$.

\section{A retórica presente no texto}

A análise retórico-literária dos textos bíblicos tem sido cada vez mais aplicada como um procedimento que permite descobrir as riquezas que neles se encerram. Por ela, novos resultados podem ser alcançados, favorecendo a percepção, a interpretação e a compreensão para além dos resultados já obtidos através dos métodos histórico-críticos, ainda considerados e praticados como fundamentais para a exegese bíblica ${ }^{21}$. A confirmação disso advém através dos três passos que se seguem.

\subsection{Análise dos períodos}

\section{a) Dt 30,11}

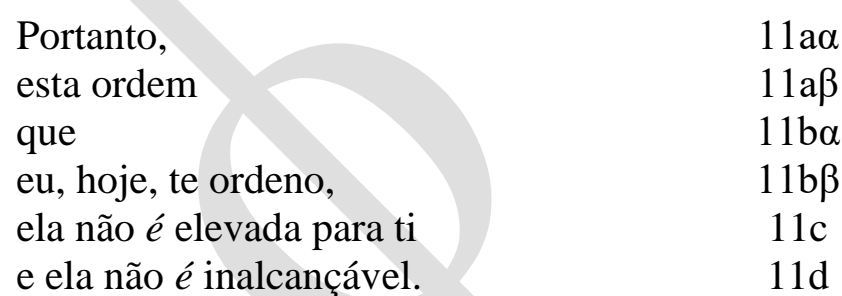

$1 \mathrm{a} \alpha$

$11 \mathrm{a} \beta$

$11 \mathrm{~b} \alpha$

$1 \mathrm{~b} \beta$

$11 \mathrm{~d}$

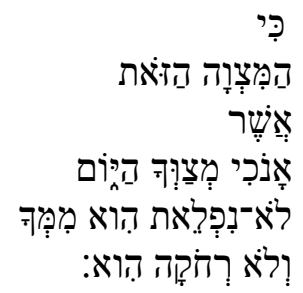

19 Cf. Erik Aurelius, «Heilsgegenwart im Wort: Dtn 30,11-14», en Liebe un Gebot. Studien zum Deuteronomium, ed. L. Perlitt; R. G. Kratz; H. Spieckermann (Göttingen: Vandenhoeck \& Ruprecht, 2000), 15.

20 A natureza proverbial de Dt 30,12-13 possui semelhanças com a forma proverbial encontrada na Mesopotâmia. Cf. Frederick E. Greenspahn, «A Mesopotamian Proverb and Its Biblical Reverberations», Journal of American Oriental Society 1, Vol. 114 (1994): 33-38. A arqueologia mostrou, por exemplo, que a expressão «subir aos céus» já constava nas cartas de Amarna, escritas no século XIV a.C., por vassalos, que viviam em Canaã, ao faraó do Egito. Cf. J. A. Knudtzon, Die El-Amarna Tafeln (Leipzig: Hinrichs, 1915), n. 264, II. 14-19; «A Pessimistic Dialogue between Master and Servant», ANET, XII, 438; expressões análogas encontram-se nas orações feitas à deusa Ishtar (ANET V, p. 383-384). A proximidade da ordem-palavra do Senhor reverte a épica imagem de que o conhecimento era inacessível ao ser humano, como no caso do reipastor Etana, que aparece na antiga lista dos reis sumerianos, e que pergunta: «Quem subiu aos céus», ANET 265. Quanto ao atravessar o mar, poderia ser uma alusão a épico sobre Gilgamesh, ANET, p. 72-99. Cf. Peter C. Craigie, The Book of Deuteronomy (Grand Rapids: William B. Eerdmans Publishing Company, 1976), 365, notas: 6 e 7 .

${ }^{21}$ Convênios bíblicos sobre a análise retórica e teses são os principais responsáveis por esse avanço. Três obras corroboram o crescente interesse dos estudiosos nesse campo. A primeira apresenta uma ampla bibliografia subdividida pelos livros bíblicos do AT e do NT: Duane F. Watson and Alan J. Hauser, Rhetorical Criticism of the Bible. A Comprehensive Bibliography with Notes on History and Method (Leiden-New York-Köln: E. J. Brill, 1994). As demais reúnem diversos estudos sobre a aplicação da retórica aos textos bíblicos de ambos os Testamentos: Roland Meynet y Jacek Oniszczuk (a cura di), Retorica Biblica e Semitica 1. Atti del primo convegno RBS (Bologna: EDB, 2009); Retorica Biblica e Semitica 2. Atti del secondo convegno RBS (Bologna: $\mathrm{EDB}, 2011)$. 


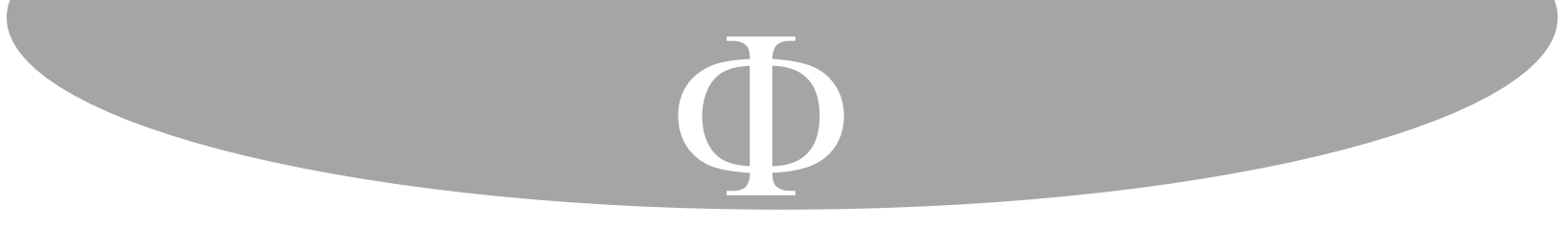

Em primeiro lugar, verifica-se que o apelo ético recai sobre a pessoa de Moisés: um líder digno de crédito pela autoridade que lhe foi confiada e confirmada pelo próprio Senhor, através dos numerosos sinais e prodígios que se operaram por suas mãos desde a saída do Egito e ao longo dos quarenta anos de estadia no deserto. Esse apelo aparece sintetizado na primeira proposição: Portanto, esta ordem que eu te ordeno... (v. 11).

Em segundo lugar, Moisés faz uso de um apelo lógico-retórico através das duas analogias que foram usadas nos vv. 12-13 e faz isso, partindo do que se poderia chamar de premissas falsas, pois as duas perguntas estão elaboradas em forma negativa, a fim de que os destinatários vejam o positivo e sejam convencidos de que a verdade é o dado oposto a elas, elemento que é confirmado pelo v. 14 .

Em terceiro lugar, verifica-se o apelo razoável que tem, como ponto de partida, a equiparação do substantivo adjetivado, esta ordem, pelo substantivo determinado por artigo, a palavra no v. 14a. Esta relação é a base do lógos que dá coesão à argumentação e que fundamenta esta ordem do v. 11a; é a razão capaz de desfazer toda e qualquer dúvida quanto à possibilidade de se refutar tanto a ordem, quanto a argumentação dos vv. 12-13.

Dentro desse terceiro apelo cabe, perfeitamente, o aceno ao aspecto emocional, pelo qual o coração, ainda que na cultura semítica represente, principalmente, a sede dos pensamentos, e seja o núcleo da vida, atesta e demonstra que o «novo Israel» não tem motivos para ser insensível à vontade do Senhor.

\section{Considerações finais}

Segundo a lógica narrativa do livro de Deuteronômio, tudo o que Moisés recebeu do Senhor, ele transmitiu, por sua vez, ao povo. É como um pai (ethos) que, antes de morrer, deixa a sua herança (logos) para o filho (pathos). Como o pai continua vivo no filho, Moisés, apesar de não entrar na terra, estará vivo na herança deixada ao «novo Israel».

De acordo com o narrador, a boca e o coração de Moisés, que serviram ao Senhor, em todo o processo de libertação e condução pelo deserto até às portas de Canaã, passam, pela ordem-palavra do Senhor, à boca e ao coração do «novo Israel».

Embora já se esteja de posse do livro da torá (Dt 30,10; 31,24.26), reside, em Dt 30,1114, a força de uma palavra oral convincente. Esse detalhe faz toda a diferença, pois a força de persuasão, que perpassa todo o livro de Deuteronômio, é a força da oralidade inigualável de Moisés, orador, interprete e exegeta da Torá; figura humana central nos discursos que concedem genialidade ao inteiro livro.

Por certo, a formulação das perguntas presume a validade da informação nas respostas que veiculam, mas, nem por isso, deixa de se fazer uso da persuasão retórica, visto que a certeza da proximidade não exclui que seu caminho seja, exatamente, o da conversão. $O$ domínio do conhecimento da Torá não é uma questão que envolve apenas privilegiados, pois todos devem ler, estudar e praticar essas leis que garantem a vida. 


\section{$\Phi$}

Watson, Duane F. and Hauser, Alan J. Rhetorical Criticism of the Bible. A Comprehensive Bibliography with Notes on History and Method. Leiden-New York-Köln: E. J. Brill, 1994.

Enviado: 16 de julio de 2020 Aceptado: 7 de septiembre de 2020

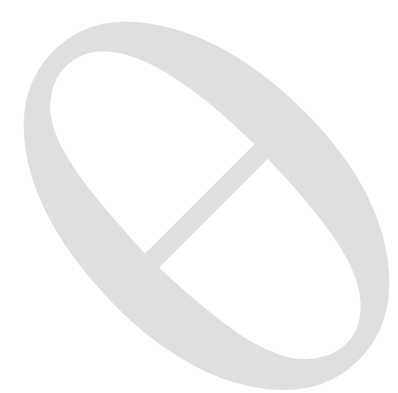

